\title{
Atypical presentation of a glomus tumour: A case report
}

\author{
Colin P White BSc(Hons) ${ }^{1}$, David D Jewer MD FRCSC ${ }^{2}$
}

\begin{abstract}
CP White, DD Jewer. Atypical presentation of a glomus tumour: A case report. Can J Plast Surg 2006;14(4):237-238.

A 46-year-old man presented with an extremely painful, $1 \mathrm{~cm}$, mobile, nodular mass located on the medial side of his right elbow. Symptoms failed to respond to conservative treatment. Ultrasound and Doppler flow imaging revealed a well-defined, round hypoechoic mass. Under local anesthesia, the mass was resected and the wound closed without complication. Final pathology diagnosed the lesion as a glomus tumour, solid type. Histology staining showed the tumour cells were positive for antibodies to vimentin and muscle actin. It is unusual for a glomus tumour to be located anterior to the medial epicondyle of the right arm. Hand surgeons most commonly encounter glomus tumours in the nailbeds of the fingers.
\end{abstract}

Key Words: Case report; Glomangioma; Glomus tumour; Elbow; Extradigital tumour; Nodular mass

\section{CASE PRESENTATION}

A 46-year-old man recently presented with a painful, $1 \mathrm{~cm}$, mobile, nodular mass located on the medial side of his right elbow. The patient's primary care physician initially believed the patient's symptoms to be consistent with medial epicondylitis (golfer's elbow). The patient's past medical history included diabetes mellitus, hypertension and osteoarthritis. He was referred to a specialist when his symptoms persisted and failed to respond to conservative treatment.

Physical examination revealed extreme tenderness at the right medial elbow anterior to the medial epicondyle, extending distally over the medial forearm area. Tapping the nodule elicited a positive Tinel's sign. On clinical examination, the mass was believed to be a neuroma of the medial cutaneous nerve of the arm. Imaging studies were arranged for the mass. Ultrasound and Doppler flow of the painful mass revealed a well-defined, round, hypoechoic mass within the subcutaneous soft tissues, measuring $10 \mathrm{~mm}$ by $9 \mathrm{~mm}$ by $11 \mathrm{~mm}$. There were prominent veins seen draping over the anterolateral aspect of the nodule and extensive vascular flow throughout. Based on the high vascularity, the mass was now thought to be a schwannoma. The patient was booked into day surgery for excision of the mass.

After local anesthesia, the mass was resected. Loupe dissection was used to identify the small cutaneous nerves in the area of the mass, and these were dissected and retracted (Figure 1). During dissection, it could clearly be seen that the mass appeared to be coming from a venous origin. Numerous veins connected to

\section{La présentation atypique d'une tumeur glomique : Rapport de cas}

Un homme de 46 ans a consulté en raison d'une masse nodulaire mobile de $1 \mathrm{~cm}$ extrêmement douloureuse sur la partie médiale du coude droit. Les symptômes n'ont pas réagi à un traitement classique. L'échographie et le Doppler ont révélé une masse hypoéchogène ronde bien définie. Sous anesthésie locale, la masse a été réséquée, et la lésion s'est fermée sans complication. La pathologie a révélé une tumeur glomique solide. La coloration histologique a indiqué que les cellules tumorales étaient positives aux anticorps de la vimentine et de l'actine. Il est inhabituel qu'une tumeur glomique se trouve sur la face antérieure de l'épitrochlée droite. En général, les chirurgiens de la main trouvent des tumeurs glomiques sous les lits d'ongles des doigts.

${ }^{1}$ Faculty of Medicine; '2Division of Plastic Surgery, Discipline of Surgery, Faculty of Medicine, Memorial University of Newfoundland, St John's, Newfoundland

Correspondence: Colin P White, C/O Student Affairs, School of Medicine, Memorial University of Newfoundland, St John's, Newfoundland A1B 3V6. Telephone 709-777-6690, fax 709-777-8296, e-mail s89cpw@mun.ca 


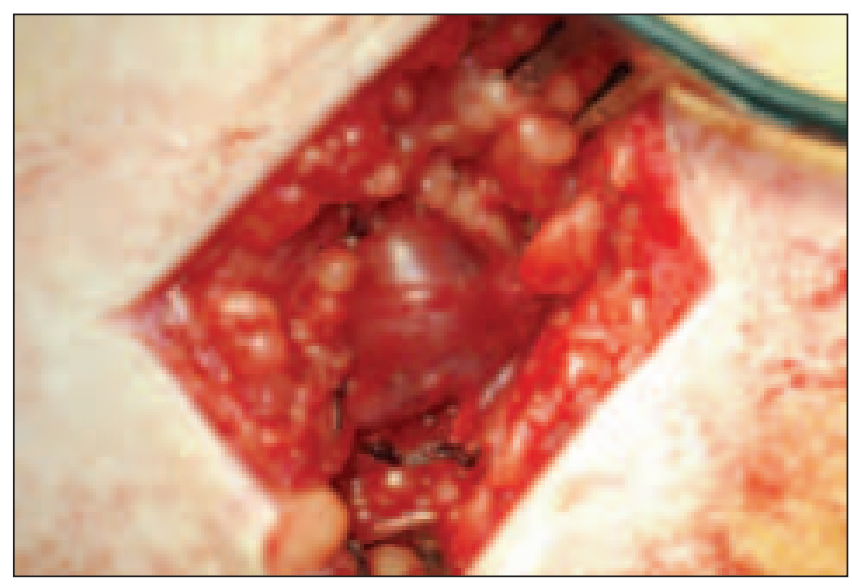

Figure 2) Close up view of the tumour in situ. Note the numerous blood vessels present on the tumour surface

blood vessels. The nodule was attached to dilated, thickwalled blood vessels. The tumour cells were positive for antibodies to vimentin and muscle actin, confirming that the mass was a glomus tumour.

It is unusual for a glomus tumour to be located anterior to the medial epicondyle of the right arm; hand surgeons most commonly encounter them in the nail beds of the fingers. The described case shows how glomus tumours, despite being a benign lesion, can cause significant symptoms, and how even after clinical suspicion and appropriate investigations, tissue diagnosis yields the only definitive diagnosis.

\section{LITERATURE REVIEW}

Glomus tumours (glomangioma) are usually benign, slow growing and exquisitely painful tumours. They arise from the modified smooth muscle cells of the glomus body, which is found in the adventitial layer of the blood vessels. The glomus body is a specialized arteriovenous anastomosis that is involved in thermoregulation (1). Glomus tumours can occur anywhere in the skin or soft tissue, even in the gastrointestinal tract. The tumour usually presents as a painful, firm, purplish, solitary nodule of the extremities, most commonly in the nail bed (2).

\section{REFERENCES}

1. Cotran RS, Kumar V, Collins T, Stanley L. Robbins Pathologic Basic of Disease, 6th edn. Philadelphia: WB Saunders Company, 1999:533-4.

2. Moor EV, Goldberg I, Westreich M. Multiple glomus tumor: A case report and review of the literature. Ann Plast Surg 1999;43:436-8.

3. Masson P. Le glomus neuromyo-arterial des regions tactiles et ses tumeurs. Lyon Chir 1924;21:257-80.

4. Lanza A, Moscariello A, Villani R, Colella G. Glomus tumor of the lower lip. A case report. Minerva Stomatol 2005;54:687-90.

5. van der Lei B, Damen A, van Valkenburg E. Compression of the lateral cutaneous nerve of the forearm by a glomus tumour. J Hand Surg [Br] 1997;22:71-2.

6. Takei TR, Nalebuff EA. Extradigital glomus tumour. J Hand Surg [Br] 1995;20:409-12.

7. Le Bellec Y, Yelles F, Kapandji T, Silbermann-Hoffman O. [Glomus tumor of forearm: A case report]. Chir Main 2005;24:99-102.

8. Googe PB, Griffin WC. Intravenous glomus tumor of the forearm. J Cutan Pathol 1993;20:359-63.

9. Beham A, Fletcher CD. Intravascular glomus tumour: A previously undescribed phenomenon. Virchows Arch A Pathol Anat Histopathol 1991;418:175-7.
This neoplasm was first fully described by Masson in 1924 (3). The presentation is generally a solitary lesion, but in some cases, multiple lesions have been described (4). In the present report, we described a glomus tumour causing clinical symptoms and signs by compression of the medial cutaneous nerve of the arm. Similar cases have been described, with the branches of the forearm nerves being compressed by venous wall tumours. van der Lei et al (5) described compression of the lateral cutaneous nerve of the forearm by a glomus tumour growing from the cephalic vein.

Cases of extradigital glomus tumours found in the forearm have also been reported (6-10). One such report described a $14 \mathrm{~cm}$ tumour in an elderly woman's right forearm, completely occluding the vein from which it grew (11). Other atypical locations on the body from which glomus tumours have been located and excised include the lower lip (4) and the mediastinum (12), and even the shoulder and upper back (6). A pathogical review (13) of 52 atypical glomus tumours showed tumour locations that ranged from the thigh $(\mathrm{n}=11)$, calf and ankle $(n=7)$, foot $(n=4)$, buttock $(n=3)$, trunk and abdomen $(n=7)$, arm $(n=9)$, wrist and hand $(n=7)$, lung $(n=2)$, stomach $(\mathrm{n}=1)$ and even the L3 vertebra $(\mathrm{n}=1)$. Other studies suggest that the frequency of extradigital cases varies from $11 \%$ to $65 \%$ and may be more common in men than women (14). It is interesting to note that in a review of the literature, there is frequent mention that, in the past, delay of diagnosis and surgery led to inappropriate psychiatric referrals (6).

In the assessment of hand tumours, it has been shown that the first method of investigation should be ultrasound (15). Magnetic resonance imaging may be useful in the detection of the tumour, but may not always be sensitive (6). Plain radiographs and angiographs tend to be normal and of no help in determining the type of mass present (10). On the basis of the previously described case, we would suggest ultrasound as the initial approach for unknown masses in the arm. Although blood vessel tumours are rare, they are frequently encountered in the hand and forearm, being the fourth most common tumour of the hand (16). Hand surgeons should be aware of the acquired, traumatic and congenital vascular tumours that are prevalent in these areas, and consider glomus tumours in the differential diagnosis of such lesions.

10. Kogure H, Shirakura K, Arisawa N, Aramaki T, Shimegi A. 3 deepseated glomus tumors in the lower arm. Acta Orthop Scand 1996;67:194-5.

11. Acebo E, Val-Bernal JF, Arce F. Giant intravenous glomus tumor. J Cutan Pathol 1997;24:384-9.

12. Gaertner EM, Steinberg DM, Huber M, et al. Pulmonary and mediastinal glomus tumors - Report of five cases including a pulmonary glomangiosarcoma: A clinicopathologic study with literature review. Am J Surg Pathol 2000;24:1105-14

13. Folpe AL, Fanburg-Smith JC, Miettinen M, Weiss SW. Atypical and malignant glomus tumors: Analysis of 52 cases, with a proposal for the reclassification of glomus tumors. Am J Surg Pathol 2001;25:1-12.

14. Beaton LE, Davis L. Glomus tumor. Q Bull Northwest Univ Med Sch 1941;15:245-54

15. Hoglund M, Muren C, Brattstrom G. A statistical model for ultrasound diagnosis of soft-tissue tumours in the hand and forearm. Acta Radiol 1997;38:355-8.

16. Palmieri TJ. Vascular tumors of the hand and forearm. Hand Clin $1987 ; 3: 225-40$ 